\title{
Stage IIIB Colorectal Cancer AJCC v8
}

National Cancer Institute

\section{Source}

National Cancer Institute. Stage IIIB Colorectal Cancer A/CC v8. NCI Thesaurus. Code C134193.

Stage IIIB includes: (T3-T4a, N1/N1c, M0); (T2-T3, N2a, M0); (T1-T2, N2b, M0). T1:

Tumor invades the submucosa (through the muscularis mucosa but not into the muscularis propria). T2: Tumor invades the muscularis propria. T3: Tumor invades through the muscularis propria into pericolorectal tissues. T4a: Tumor invades through the visceral peritoneum (including gross perforation of the bowel through tumor and continuous invasion of tumor through areas of inflammation to the surface of the visceral peritoneum). N1: One to three regional lymph nodes are positive (tumor in lymph nodes measuring $0.2 \mathrm{~mm}$ or more), or any number of tumor deposits are present and all identifiable lymph nodes are negative. N1c: No regional lymph nodes are positive, but there are tumor deposits in the subserosa, mesentery, or nonperitonealized pericolic, or perirectal/mesorectal tissues. N2a: Four to six regional lymph nodes are positive. N2b: Seven or more regional lymph nodes are positive. MO: No distant metastasis. (AJCC 8th ed.) 